\title{
Commercial Buildings Partnership Projects - Metered Data Format and Delivery
}

S Katipamula

November 2010

\section{Pacific Northwest}

NATIONAL LABORATORY

Proudly Operated by Battelle Since 1965 


\section{DISCLAIMER}

United States Government. Neither the United States Government nor any agency thereof, nor Battelle Memorial Institute, nor any of their employees, makes any warranty, express or implied, or assumes any legal liability or responsibility for the accuracy, completeness, or usefulness of any information, apparatus, product, or process disclosed, or represents that its use would not infringe privately owned rights. Reference herein to any specific commercial product, process, or service by trade name, trademark, manufacturer, or otherwise does not necessarily constitute or imply its endorsement, recommendation, or favoring by the United States Government or any agency thereof, or Battelle Memorial Institute. The views and opinions of authors expressed herein do not necessarily state or reflect those of the United States Government or any agency thereof.

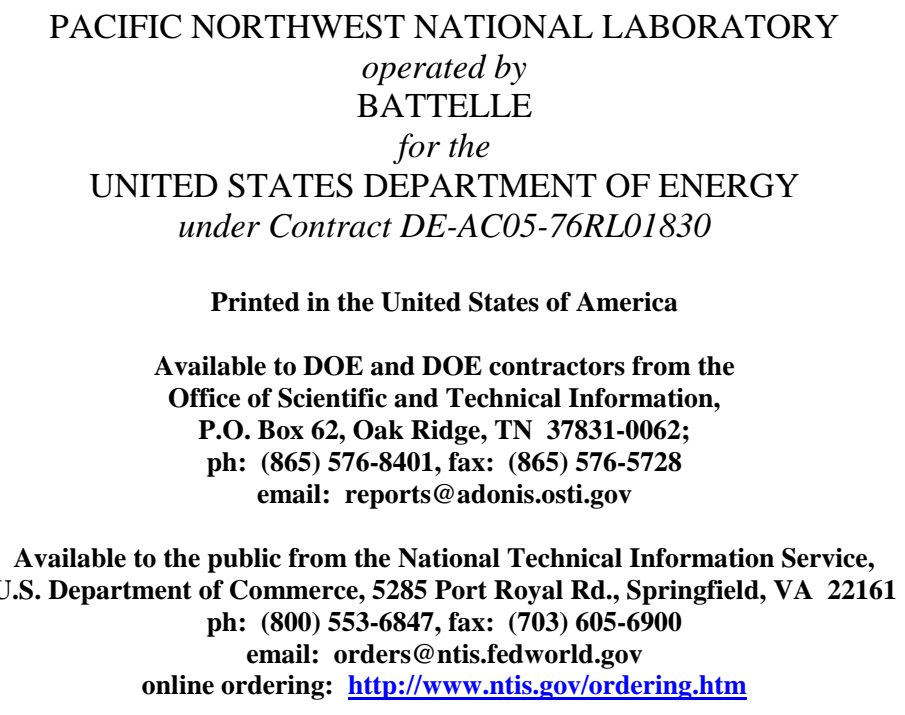

This document was printed on recycled paper.

$(8 / 00)$ 
PNNL-19999

\section{Commercial Buildings Partnership Projects - Metered Data Format and Delivery}

S Katipamula

November 2010

Prepared for

U.S. Department of Energy

under Contract DE-AC05-76RL01830

Pacific Northwest National Laboratory

Richland, Washington 99352 


\section{Table of Contents}

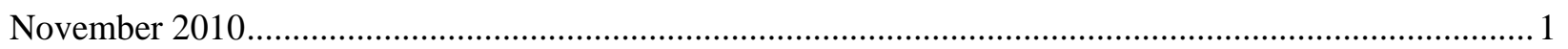

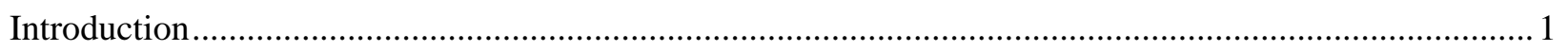

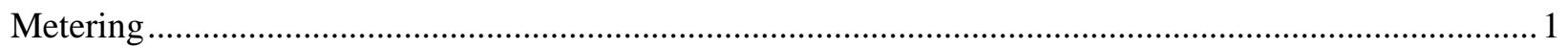

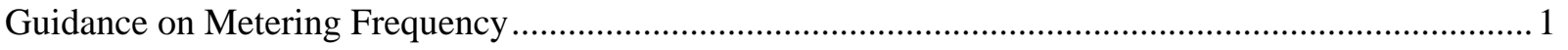

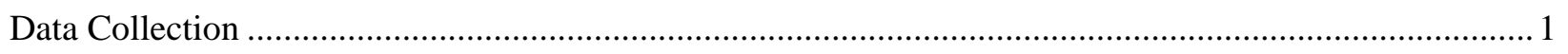

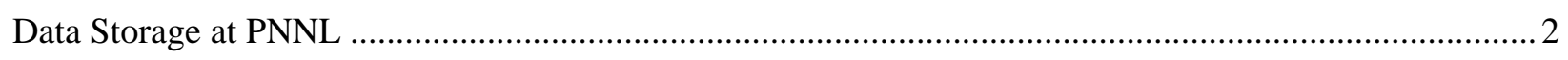

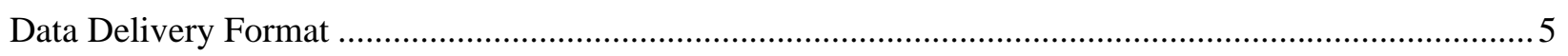

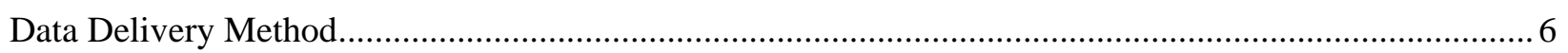

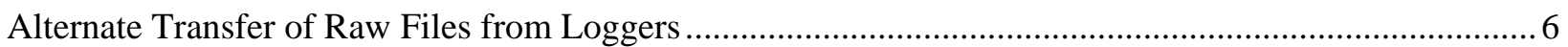




\section{Introduction}

A number of the Commercial Building Partnership Projects (CBPs) will require metering, monitoring, data analysis and verification of savings after the retrofits are complete. Although monitoring and verification $(\mathrm{M} \& \mathrm{~V})$ agents are free to use any metering and monitoring devices that they chose, the data they collect should be reported to Pacific Northwest National Laboratory (PNNL) in a standard format. PNNL will store the data collected in its CBP database for further use by PNNL and the U.S. Department of Energy.

This document describes the data storage process and the delivered format of the data from the measurement and verification $(\mathrm{M} \& \mathrm{~V})$ agents.

\section{Metering}

There are a number of reasons for metering major energy end-uses (electricity, plug loads, lighting, process loads, etc) and specific heating, ventilation and air-conditioning (HVAC) systems. Metering is typically done to:

1. Establish occupancy schedules and schedules for end uses (plug loads, lighting, HVAC equipment, process loads, etc)

2. Estimate efficiency or characterize the detailed performance of major HVAC systems (chillers, boilers, roof-top packaged units, etc)

3. Estimate power densities (lighting, plug loads, miscellaneous process loads)

4. Establish setup points (heating/cooling, static pressure, etc)

5. Calibrate energy simulation models

6. Verification of savings from retrofits to major end uses or HVAC systems.

The first step in this process is for the $\mathrm{M} \& \mathrm{~V}$ agent to develop a metering plan to meet the needs for the analysis proposed by the modeling agent. The metering plan should outline what will be metered and how it will be metered. In addition, the metering plan should also identify the frequency of data samples. The plan should also recommend how frequently the data should be retrieved and the method of retrieving (on-site visit or phone or local area network etc).

\section{Guidance on Metering Frequency}

Although the analysis needs will dictate the data collection frequency, for most analysis needs, hourly data will be sufficient. In some cases, sub-hourly might be needed (for example, to establish run-times for equipment that turns ON/OFF more frequently than hourly). To verify savings from retrofit, in most cases, daily energy consumption would be sufficient, but it if the budget allows data should be collected hourly.

\section{Data Collection}

Once the meters are in place, it is time to periodically retrieve the data. The retrieval method and frequency at which it occurs will depend on the type of meters installed. Some meters will require a periodic visit to the site (once a week or month) to collect the data from the installed meters/loggers, and bringing it back or emailing the data to the data analysis lead at PNNL. Other meters may have remote 
monitoring capabilities, where M\&V staff can periodically download the data over the phone or local area network and provide the data to the data analysis lead and PNNL. The frequency of download (especially for site visits) is critical because there will be a finite amount of storage on the loggers. The metering plan will identify how frequently the data should be retrieved and the method of retrieval.

Naming the data files is critical because there will be a huge number of files over time. As a result, proper procedures are to be followed when naming the data files. In some cases the data files will only have one data point. However, in some cases, there will be multiple data points in a single file. If the files contain multiple data points, each data point should be appropriately labeled.

The required naming convention for the files is: Site.LocationWithinSite.EndUse.Date.Initials.csv, where

- "site" is a unique three digit site ID that is pre-assigned to each site, for example, the site ID for Crowne Plaza is "100.” Site IDs for the rest of the sites will be pre-assigned by PNNL and provided at the request of the M\&V agent.

- "LocationWithinSite" indicates where the meter was installed, for example, while metering loads in a guest room in Crowne Plaza the guest room number (201) should be used or if a meter is installed in an air-handling unit (AHU), the AHU number (AHU-1) should used.

- "EndUse" refers to the actual point that is being measured, for example, use "PTHP-Amp" to indicate a current measurement in a packaged terminal heat pump.

- "Date" refers to the date the data was downloaded, use "MM-DD-YYYY" format.

- "Initials" refers to the person who downloaded the file.

- Finally, the file extension should be noted, " $c s v$ " refers to the file type, which is comma separated file format. For space or tab delimited files use a " $t x t$ " extension.

\section{Data transferred to PNNL should be either ASCII text or ASCII comma separated variable format (csv). PNNL will not accept any binary or proprietary formats of data.}

\section{Data Storage at PNNL}

PNNL stores data in a MySQL ${ }^{1}$ database. MySQL is a popular open source database that has good performance, is highly reliable and is easy to use. The database currently has four tables that are relationally linked: 1) meterdata, 2) meters, 3) buildings and 4) utilitydata.

The "buildings" table has relevant information about the building (or site) as shown below.

\footnotetext{
${ }^{1}$ www.mysql.com
} 


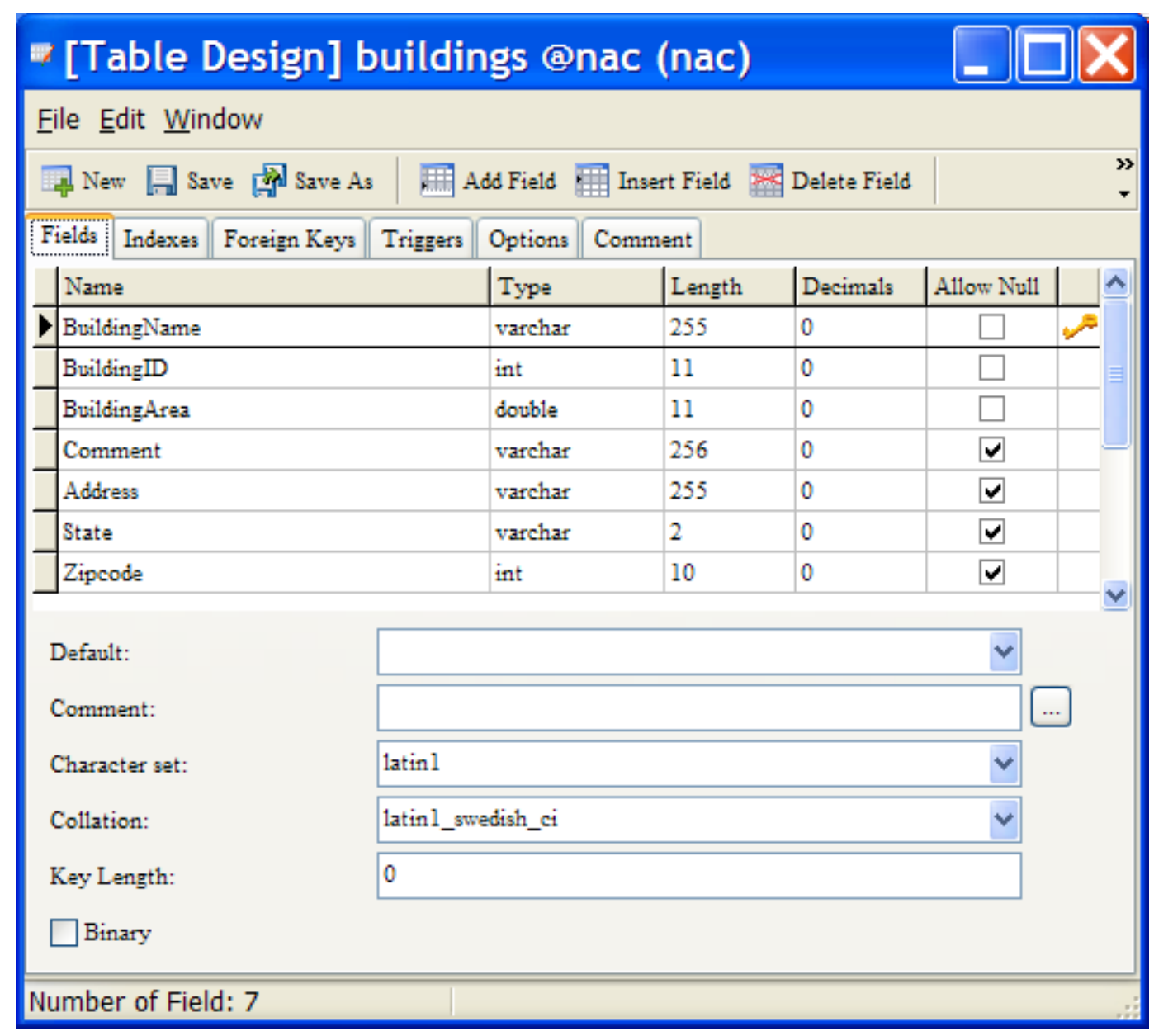

M\&V agent should provide all relevant building information before the start of data transfer to PNNL. After PNNL receives this information, PNNL will provide a unique site ID for the building. 
The "meters" table has the relevant information about each of the meters as shown below.

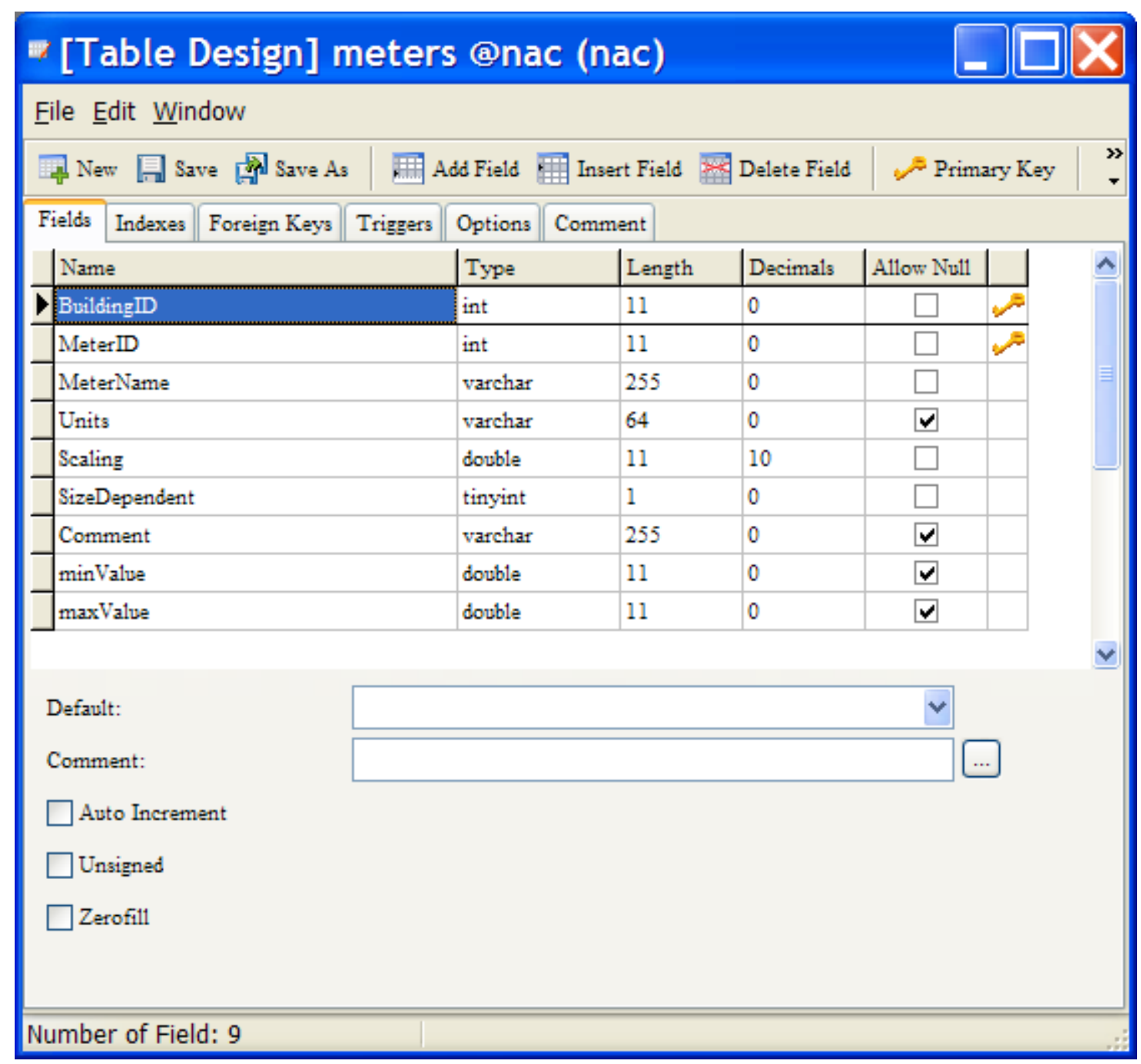

As soon as the metering plan is developed and approved by the design consultant, the M\&V agent should provide that information to PNNL. At a minimum, PNNL will need a list of meter names and the units for each of the meter values. The meter names should be unique and should not be longer than 255 characters. M\&V agents can assign unique meter IDs for each of the meter points. PNNL recommends that meter ID " 1 " be assigned to whole building electricity consumption and meter ID " 2 " for outdoor air temperature. If whole building electricity or outdoor air temperature is not monitored at this site, start the meter IDs numbering sequence with "3.” Make sure that within each building, the meter IDs are unique.

The variable "scaling" is used to scale non-hourly energy consumption data to hourly values, a value of ' 1 " for scaling implies no scaling. If the consumption data in kWh is collected every 15-minutes, the scaling field will have a value of "4." A value of " 1 " for "SizeDependent" variable indicates that the variable can be normalized. The minValue and maxValue inputs for each meter are used to check the range of the metered data. So, the $M \& V$ agent should provide reasonable minimum and maximum values for each of the meter data points. PNNL will provide an example spreadsheet that will show all of the relevant information that is needed. Please use the spreadsheet to customize it to your needs. 
The "meterdata" table (as shown below) is used to stores all metered data. Each record in the table is uniquely associated with a building, meter, and with a unique date and time stamp. No duplicate values are allowed. If duplicate values are provided, only the first value will be used, and subsequent values will be ignored during the transfer of data to the database.

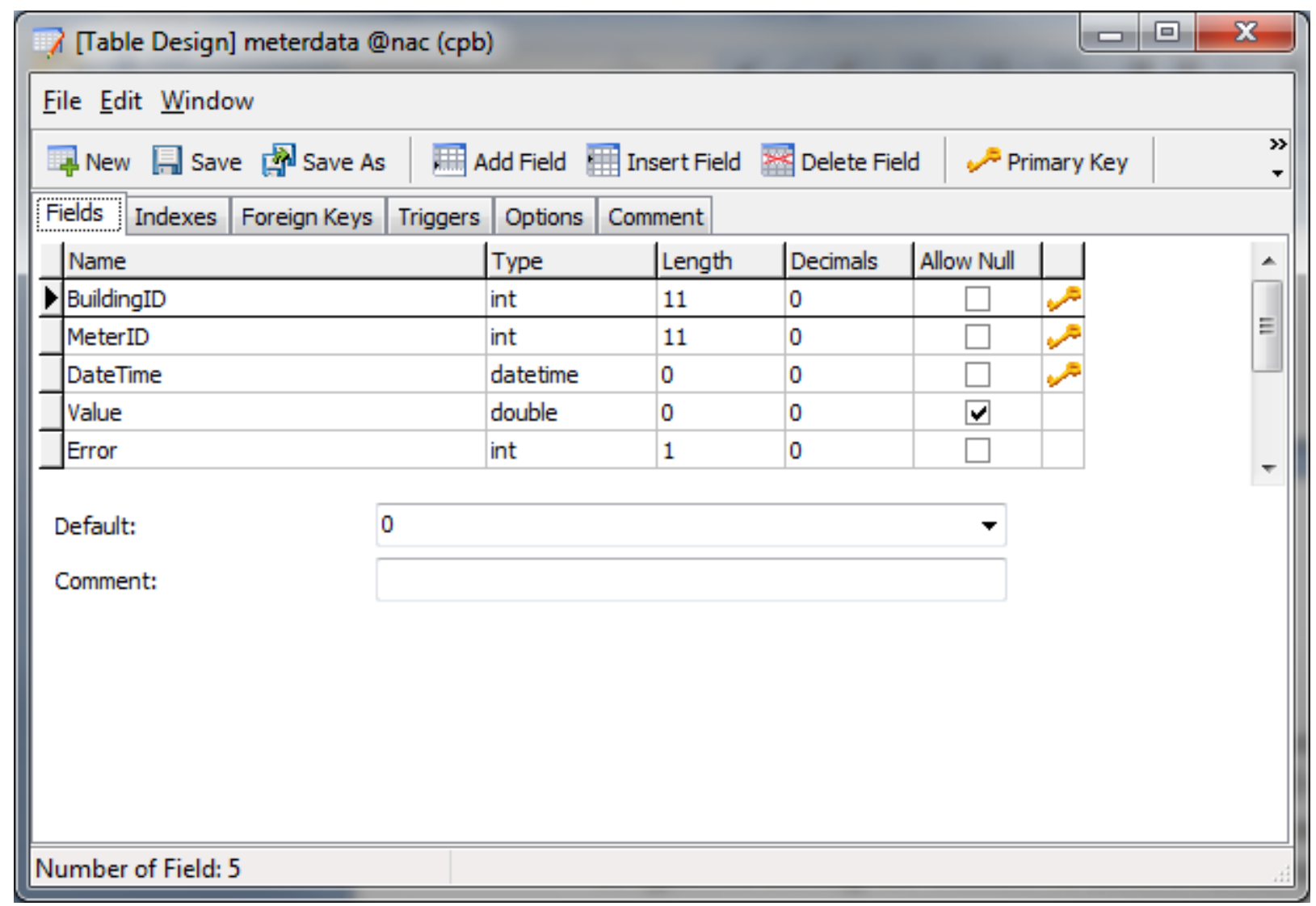

\section{Data Delivery Format}

As noted earlier, the preferred data format is ASCII files with values separated by a comma, commonly also known as "CSv" format. If for some reason data cannot be delivered in CSV format, PNNL will make exceptions and work with the $M \& V$ agent to find an alternate format for the data to be delivered to PNNL.

The $\operatorname{csv}$ file should be in the following format. Please note the order in which the various columns are provided is important. If you are not able to provide the data in the following format, PNNL will make exceptions.

Building ID, Meter ID, Date and Time Stamp, Value, Error

1. Building ID is an unique ID that PNNL assigns to each building in the CBP project

2. Meter ID is an unique ID for each meter assigned by the M\&V agent or PNNL

3. Date and time stamp for the meter point

4. Value of the meter point at a given date and time stamp 
5. Error field should generally have a value of " 0 " if the quality of data is good. If for some reason the values are bad, the field should be marked with a " 1 " (indicating bad data).

Please note the format of the date and time stamp in the example data shown below:

BuildingID, MeterID, yyyy/mm/dd hh:mm:ss, value, error

100, 1, 2010/01/01 15:15:00, 1500.0, 0

$100,1,2010 / 01 / 01$ 15:20:00, 1550.0, 0

$100,1,2010 / 01 / 01$ 15:25:00, 1580.0, 0

$100,1,2010 / 01 / 01$ 15:30:00, 1500.0, 0

$100,1,2010 / 01 / 01$ 15:35:00, 1520.0, 0

$100,1,2010 / 01 / 01$ 15:40:00, 1530.0, 0

100, 1, 2010/01/01 15:45:00, -99.0, 1

100, 1, 2010/01/01 15:50:00, -99.0, 1

\section{Data Delivery Method}

There are a number of ways that the data files can be delivered to PNNL:

1. Emailing them to the designated PNNL staff member

2. PNNL file transfer website (recommended for large files) - instructions on how to access the site will be provided on request

3. Putting the files on a CD/DVD and mailing them to designated PNNL staff member

\section{Alternate Transfer of Raw Files from Loggers}

PNNL has developed processing routines for select loggers. Although raw file transfer is not a preferred approach, PNNL will consider this mode of file transfer. PNNL can handle the raw files from the following loggers:
1. HOBO
2. Watts Up
3. Madgetech
4. Campbell Scientific. 


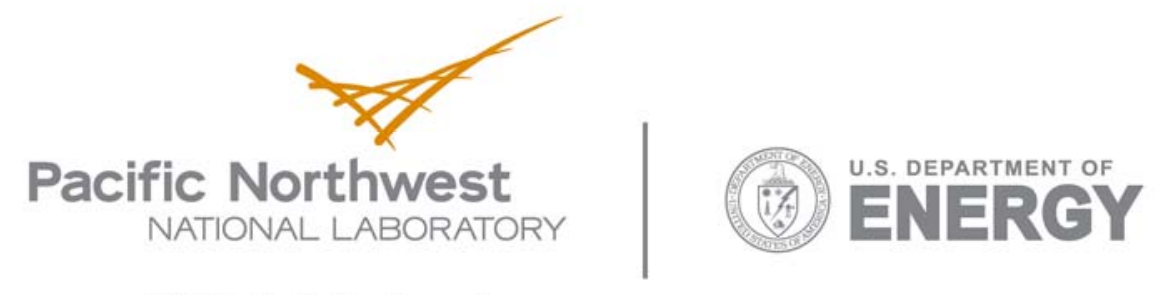

902 Battelle Boulevard

P.O. Box 999

Richland, WA 99352

1-888-375-PNNL (7665)

www.pnl.gov 